\title{
Psychologists as "the quiet ones with the power": Understanding indeterminate sentenced prisoners' experiences of psychological risk assessment in the United Kingdom
}

Jo Shingler*1, Stefanie J. Sonnenberg ${ }^{2}$, and Adrian Needs ${ }^{3}$

'Department of Psychology, University of Portsmouth, United Kingdom; ' Department of Psychology, University of Portsmouth, United Kingdom; 'Department of Psychology, University of Portsmouth, United Kingdom

${ }^{*}$ Corresponding author information: Jo Shingler, Department of Psychology, University of Portsmouth, King Henry Building, King Henry $1^{\text {st }}$ Street, Portsmouth PO1 2DY, UK, (joanne.shingler@port.ac.uk; up707929@myport.ac). 


\section{Psychologists as "the quiet ones with the power": Understanding indeterminate sentenced prisoners' experiences of psychological risk assessment in the United}

\section{Kingdom}

Prisoners serving indeterminate sentences in the United Kingdom do not know when or if they will be released from prison. Release and progression decisions are determined by the risk the ISP presents of reoffending. This makes the assessment of risk a high stakes business for ISPs. Whilst there is a large body of literature focused on prisoners' general experiences of prison, there is an absence of specific empirical exploration of prisoners' experiences of risk assessment. This paper aims to address this gap by reporting the results of a qualitative exploration of ISPs' experiences of psychological risk assessment. Interviews with 10 ISPs were conducted and analysed using Grounded Theory methods. Analysis indicated that prisoners experienced the prison environment as characterised by violence, volatility and suffering. Psychological risk assessment is embedded within this emotionally and physically challenging context but also contributes to the experience of suffering. Within this context, prisoners felt stuck, powerless and out of control in relation to risk assessment, and experienced psychologists as untrustworthy yet powerful. Understanding prisoners' experiences is the first step in resolving some of the long-reported difficulties in working relationships between psychologists and prisoners as well as making the process more procedurally just.

Key words: risk assessment; indeterminate sentence; prisoners; psychological assessment; grounded theory

Word count: 9,432 


\section{Introduction}

Psychological risk assessment is central to the lives of indeterminate sentenced prisoners (ISPs), whose progression through the prison system towards release is dependent on favourable risk assessment outcomes. However, there is little empirical research into ISPs' experiences of risk assessment, a gap this paper aims to address.

\section{The workings of the indeterminate sentence}

ISPs in the United Kingdom have no fixed release date - they do not know when or if they will be released. Most ISPs ${ }^{4}$ are given a tariff which refers to the minimum time they must serve in custody. ${ }^{5}$ After tariff expiry, prisoners are eligible to be considered for release by the Parole Board, the decision making body for ISPs in England and Wales. That is, the end of the tariff does not mean the end of the sentence. Instead "the law states that the offender is no longer held in prison as a punishment and can only remain in prison if they pose a risk to the public" (The Parole Board, 2018, "Parole Board Information on Indeterminate Sentenced Prisoners", para. 1, emphasis added). The Parole Board "may only direct the release of a life sentenced prisoner if it is satisfied that it is no longer necessary for him/her to be detained in order to protect the public from serious harm" (The Parole Board, 2018, "Parole Board Information on Indeterminate Sentenced Prisoners", para. 3). The Parole Board also has a role in making recommendations about a prisoner's progression through the system including transfer to open prison conditions, which is, in most cases, the first step towards release. ${ }^{6}$ In sum, ISPs are dependent on favourable risk assessments in order to progress towards eventual release.

\footnotetext{
${ }^{4}$ In the United States the equivalent sentence is "life sentence with the possibility of parole".

${ }^{5}$ The exception to this is prisoners who are given a "whole life" tariff, and who will consequently never be released from prison. At the end of December 2018 there were 63 whole life prisoners in England and Wales comprising around $0.7 \%$ of the total population of indeterminate sentenced prisoners (Ministry of Justice, 2019). ${ }^{6}$ Whilst the Parole Board makes a direction for release that cannot be overturned, it is only permitted to make a recommendation for transfer to open prison conditions. Such a recommendation can be overturned by the Secretary of State.
} 


\section{ISPs and risk assessment}

Indeterminate sentences are generally only given for the most serious offences, and arguably where risk to the public is the greatest. ${ }^{7}$ Decisions to release ISPs can attract considerable media scrutiny (e.g., Engineer \& Rogers, 2018). Failures in the management of ISPs and seemingly incorrect risk assessments can have catastrophic consequences (Her Majesty's Inspectorate of Probation - HMIP, 2006). This makes the process of risk assessment a challenging and complex process for all involved (Shingler, Sonnenberg \& Needs, 2019; Austin, Kagan, Rankel \& Bergum, 2008).

In order to reach decisions about the progression of ISPs, the Parole Board considers a wide range of information including the nature of the prisoner's offending, the prisoner's insight into his risk and his progress in prison, and the opinions of prison staff, including psychologists. In many cases, oral hearings are held in which professionals and the prisoner are closely questioned by panels of the Parole Board in order to test the strength of their evidence for and against the presence or absence of risk. In practice, psychological evidence is central to Parole Board decision making (Bowers \& Friendship, 2017; Shingler, 2017; Shingler \& Needs, 2018a; Shingler, et al., 2019; Sparks, 1998). It has been suggested that prisoners believe psychologists hold "the key to captivity or release" (Crewe, 2012, p.121) in relation to Parole Board decision making. This renders psychological risk assessment a high stakes business for ISPs.

\section{Prisoners' involvement in psychological risk assessment}

There is evidence that overall, "mechanical" risk assessment procedures (i.e., actuarial risk assessment instruments or ARAIs) provide the most accurate predictions of recidivism (Hanson \& Morton-Bourgon, 2009). Completion of an ARAI does not require the

\footnotetext{
${ }^{7}$ More details about the nature of indeterminate sentences can be found at https://www.justice.gov.uk/offenders/types-of-offender/life
} 
engagement or cooperation of the prisoner as, in most cases, it is based on pre-existing records. However, in practise, the goals of risk assessment to inform Parole Board decision making are broader than prediction of reoffending (Heilbrun, Yasuhara \& Shah, 2014). Psychological risk assessment requires psychologists to consider the nature and imminence of risk; the nature and extent of the psychological (dynamic) risk factors; the nature and extent of existing protective factors; the psychological, social or environmental interventions that would be most useful in reducing or managing risk; and the suitability of the prisoner for release or transfer to less secure prison conditions (Shingler, et al., 2019; Vess, Ward \& Yates, 2017). Additionally, Parole Board members (PBMs) want to understand the psychological factors underpinning risk (Shingler, 2017; Shingler \& Needs, 2018a) and believe that this helps them to make fairer and better informed decisions (Shingler, 2019). Additionally, the challenges of relying on ARAIs, which are based entirely on nomothetic data, to reach conclusions about the risk presented by a specific individual have been debated at length in the literature (Barnett \& Mann, 2011; Dematteo, Batastini, Foster \& Hunt, 2010; Hart, Michie \& Cooke, 2007). In order to meet these broad and varied requirements of risk assessment, psychologists need to convince prisoners to engage in the risk assessment process. This usually comprises one or more interviews, in which the prisoner's offending, background, problems and strengths are explored in detail (Shingler, Sonnenberg \& Needs, 2017). This requires considerable skill on the part of the psychologist (Logan, 2013; Shingler et al., 2017). It also requires engagement and trust on the part of the prisoner. However, there is literature to suggest that relationships between prisoners and prison-based psychologists are characterised by hostility and suspicion (Crewe, 2011; Gannon \& Ward, 2014; Maruna, 2011; Shingler et al., 2019; Warr, 2008). There is also a suggestion that prisoners see psychologists as unjustifiably powerful and tend to attribute hostile motives to them. It seems 
unlikely that prisoners will engage fully in what could be a stressful and demanding process if they feel suspicious and anxious (Crighton, 2010; Marshall, 1994).

There is a related suggestion that risk assessment is a generally negative experience for prisoners. Attrill and Liell (2007) found that risk assessment was perceived as one of the most stressful aspects of the life sentence. It was seen largely as unfair due to the focus on past behaviours, and neglect of change, progress and strengths. In a broader exploration of prison life, Crewe (2011) referred to psychological risk assessment as a form of purgatory, particularly for ISPs who felt unsure of how to navigate the opaque environment of assessment without becoming “...entangled [....] in the carceral net” (p. 516). Similarly, Liebling (2011) commented on the threat of risk assessment affecting prisoners' ability to trust and minimising their sense of self efficacy, leaving them feeling trapped, vulnerable and hopeless. Liebling commented that, "in this unsafe environment, the experience of being scrutinised and assessed was life-sapping" (p. 542).

Despite these suggestions, detailed empirical exploration of prisoners' views of psychologists and psychological risk assessment is absent from the extant literature. Given the significance of risk assessment for the lives and futures of ISPs, it is surprising that so little is known about their experiences. The value of understanding prisoners' experiences of risk assessment lies in enabling practitioners to maximise engagement and cooperation with the process. Criminal justice decisions that are perceived as procedurally just are much more likely to be complied with - feeling that one has a voice and a stake in such decisions as well as having trust in the decision maker are key elements of procedural justice (Leventhal, 1976; Tyler, 1990; Tyler \& Huo, 2002). There is also evidence that lack of cooperation with supervision and risk management attempts is associated with increased risk (Hanson \& Morton-Bourgon, 2004). Therefore, encouraging engagement with risk assessment and risk management arguably results in better outcomes for prisoners and the public (Proulx, Tardif, 
Lamoureax \& Lussier, 2000) as well as better informing the risk assessments presented to the Parole Board.

This study aimed to fill the gap in the literature by specifically investigating ISPs' experiences of having risk assessments completed on them by psychologists. The findings reported below form part of a larger project that aims to provide an in-depth, multi-faceted exploration of the process of psychological risk assessment. Issues relating to the broader context of the risk assessment process will be analysed and reported in due course. Here, we focus on addressing the following specific question:

- What are indeterminate sentenced prisoners' experiences of having risk assessments completed on them by psychologists?

\section{Method}

\section{Participant recruitment}

Approval for the study was obtained from the National Offender Management Service (NOMS) National Research Committee (NRC) and the University's Ethics committee. Access to participants was negotiated separately with two prisons in England, geographically convenient to the interviewer. ${ }^{8}$ Prison 1 was a Category B establishment and Prison 2 was a Category $\mathrm{C}$ establishment. ${ }^{9}$ Ten adult male prisoners, three from prison 1 and seven from prison 2 were interviewed between April 2015 and February 2016. All interviews were conducted by the first author in private interview rooms within the prisons.

\footnotetext{
${ }^{8}$ Prisoner recruitment was dependent on local procedures and permissions. In Prison 1 , local staff provided us with a list of men who met the inclusion criteria, from which we randomly selected five men to contact in writing to invite to participate. Three men agreed to participate; the remaining two did not reply. In Prison 2, a local manager asked staff to provide names of potential participants who met the inclusion criteria. The first author met the seven men identified and all agreed to participate.

${ }^{9}$ Prisoners are given a security category depending on their likelihood of escape, and the risk they are considered to present to prison staff and other prisoners. Category B prisons are for prisoners who do not need the highest level of security but '..for whom escape must be made very difficult' (Ministry of Justice (MOJ) 2011 , p. 6). Category C prisons are for '...prisoners who cannot be trusted in open conditions but who do not have the resources and will to make a determined escape attempt' (ibid).
} 
Prisoners were eligible for inclusion in the study if they were men, over the age of 18 , currently serving an indeterminate sentence in a Category B, C or $\mathrm{D}^{10}$ establishment, and had undergone a psychological risk assessment during their current sentence. Prisoners were excluded if they were identified in prison records as presenting a current risk of harm to themselves or to staff; if they were currently receiving treatment for psychosis; if they were not able to speak English; or if they were subject to deportation arrangements. A summary of the characteristics of the prisoner participants can be found in Table 1.

\section{Insert Table 1 here}

\section{Materials}

An interview guide was developed in advance of data collection in order to facilitate exploration of the following areas: (1) prisoners' experiences of, and thoughts and feelings about psychological risk assessment (2) their views on the professional relationship between prisoners and psychologists during risk assessment interviews, (3) their views on the high stakes nature of risk assessment for ISPs, and (4) their overall perspectives on what constitutes effective and ineffective practice in psychological risk assessment. These areas were explored flexibly and responsively with participants. Initial questions were phrased openly in order to maximise freedom of response within the relevant area. For example, the first question was "What I am most interested in is your experiences of having risk assessments completed on you by psychologists. Can you tell me a bit about what that has been like for you?"

\section{Procedure}

\footnotetext{
${ }^{10}$ Category D prisons are for prisoners who present a low risk and '... whom can be reasonably trusted no to abscond' (MOJ, 2011). There were no Category D prisoners in the research sample.
} 
Individual interviews varied in length, depending on the contributions of the participants, with an average length of 58 minutes. All prisoners were unknown to the interviewer. Steps were taken to enable prisoners to feel comfortable and confident about the purpose of the interview and the boundaries of confidentiality. The interviewer was both a researcher and an experienced forensic psychologist. This meant that she was able to respond flexibly to prisoners' contributions, using her knowledge and experience where helpful to explore issues. She remained mindful of the need to understand the perspectives of participants, whilst also remaining aware of the impossibility of separating herself entirely from the interview process (Charmaz, 2006). She was open with the prisoners about her role and her experience and made it clear that she was interested in hearing about their experiences, both positive and negative.

Interviews were recorded using a digital voice recorder and transcribed by the interviewer using a transcription convention adapted from Edwards and Potter (1992). ${ }^{11}$ All identifying information was removed, and each participant was allocated a pseudonym ${ }^{12}$.

\section{Analytic approach}

Data collection and analysis followed Grounded Theory (GT) principles. The specific GT approach adopted here is described in detail by Urquhart (2013) and also drew on principles outlined by Glaser and Strauss (1967) and Charmaz (2006). As noted earlier, this paper forms part of a larger Grounded Theory project and therefore no claims to theory development are made at this point. The analytic process consisted of three levels of coding: open coding, selective coding and theoretical coding. However, as GT analysis is generally conceptualised as an iterative process, coding, categorising, and data collection occurred simultaneously and informed each other.

\footnotetext{
${ }^{11}$ The transcription conventions used are available from the first author on request.

${ }^{12}$ Each pseudonym is used consistently to refer to the same participant both in this paper and in other publications arising from the larger project.
} 
Open coding involved line-by-line analysis of each transcript and the identification and labelling of discrete units of meaning (Charmaz, 2006; Urquhart 2013). This was conducted by the first author. Selective coding (Urquhart, 2013) involved looking for different examples of the same open codes both within and across interviews, whilst remaining attentive to the presence of new ideas. Additionally, open codes that seemed to describe different dimensions of the same concept were grouped together. Theoretical coding involved identifying broader categories which could help to explain the relationships between selective codes, and under which selective codes could be grouped.

Validity of the emerging codes was discussed and refined with the second author. The overall analysis was checked with the research term (peer debriefing, see Creswell \& Miller, 2000; see also Urquhart, 2013). We also engaged in a member checking exercise (Creswell \& Miller, 2000) in which the preliminary results were discussed with an ISP who was currently on license in the community.

\section{Findings and discussion}

The results are summarised in Figure 1 below. First, and consistent with psychologists' experiences (Shingler, et al., 2019), analysis revealed a negative impact of the prison environment, described by the superordinate category "Volatility, Violence, Suffering". This is depicted as the backdrop to the other aspects of prisoners' experience, as prisoners and risk assessment are embedded within, and impacted by the prison environment. Within this environment, and depicted as more directly related to risk assessment, are two sub-categories of meaning, namely "Feeling Stuck, Powerless and out of Control" and "Psychologists as Untrustworthy yet Powerful". In the interviews, prisoners spontaneously talked about aspects of their lives in prison that were not directly related to risk assessment. It is likely, therefore, that these categories are relevant to the experience of serving indeterminate sentences more broadly. However, risk assessment was described by a number 
of participants as being part of the prison experience so it is reasonable to conclude that issues affecting prisoners generally also affected them in relation to risk assessment. Finally, the category labels reflect negative experiences as these are most commonly described. Nonetheless, a number of prisoners described greater self-efficacy in relation to managing their life sentences, a more positive attitude towards the prison system and more positive relationships with psychologists. These experiences are described where relevant to each category to provide balance, and as ideas for overcoming the more pervasive negative attitudes and experiences described by participants.

\section{Insert Figure 1 here}

\section{Volatility, violence, suffering}

Colin described how "there's suffering going on that, that people don't know about" in prison, and it is within this context of suffering that psychological risk assessment is conducted. Prisoners described a range of areas of suffering including threats to their physical safety, emotional and interpersonal suffering, feeling disconnected from their lives outside of prison and feeling infected by prison culture and norms. The sense of prison as causing suffering is consistent with extant literature (De Viggiani, 2006 \& 2007; Irwin \& Owen, 2005; Liebling \& Maruna, 2005; Sykes, 1958). Examples of prisoners' experiences of suffering involved fearing violence, witnessing violence, or being the target of threats or actual violence (see Butler, 2008). John described his experiences of violence in prison, where physical assaults came out of nowhere, and "the slightest little thing can escalate":

I mean I've seen guys get their throat cut over moving somebody's toast on the toaster. I couldn't believe, that was a shock to me. I'd never seen anything like that in my life, but that's what you're dealing with. 
De Viggiani’s (2007) prison ethnography described similar examples of extreme violence arising from insignificant events and Sim (1994) reflected on violence as central to prison life. Blagden and Perrin (2016) described the impact of constant fear for personal safety amongst a group of sexual offenders; fear interfered with prisoners' ability to think and reflect on their problems and past behaviour, something that is an essential requirement of risk assessment.

Emotional and interpersonal suffering was described by a number of participants (as well as by Irwin \& Owen, 2005; Liebling \& Maruna, 2005; Sykes, 1958). Malcolm described how he felt "suffocated" in prison, and Daniel described how emotions were repressed ${ }^{13}$ (De Viggiani, 2006), meaning “it's hard cos you haven't really got an outlet” when feeling stressed or angry. Peter felt that prison "makes you more bitter against the system" which he felt had done nothing to rehabilitate him (see also De Viggiani, 2007; James, 2003). Peter experienced prison as harsh and degrading:

They treat you like dogs and expect you to behave like saints, and it doesn't work like that. You can't kick a dog and expect it to love you, you know, but that's, that's how the system works.

Malcolm described suffering resulting from being separated from families:

My mum, my grandmother, she got kids bangin on her front door tryin to rob her. Yeah because these are real things y'see, y'see when you're a lifer, you're powerless n'that yeah for things outside. You only got phone calls, n'you got people round you n'that yeah, it's hard n'that if you've got kids n'things, you your girlfriend's in prison or summin, your girlfriend's on drugs, or your girlfriend's outside, or she's struggling

\footnotetext{
${ }^{13}$ Crawley (2004) similarly suggests that working in prisons results in prison officers supressing feelings of concern and compassion for prisoners. This would imply that the prison environment itself has an impact on emotional expression, rather than this being solely a psychological characteristic of some prisoners.
} 
to come to visit you, n'sometimes those are the most important things to a lifer, cos this is your people, it's the bond.

It was apparent that Malcolm found it difficult to cope with the worry about his family and the sense of powerlessness he had as an ISP to do anything to help his family (powerlessness will be discussed in more detail in the next section). Schinkel (2014) described a similar sense of powerlessness over outside relationships amongst her sample of long term prisoners. Schinkel's participants coped with long sentences by narrowing their horizons to their prison lives, trying to shut out the outside, including blocking contact with family and friends and "keeping your head inside the walls" (p. 73). This approach implies that some prisoners cope with prison via role segmentation (Ashforth, Kreiner \& Fugate, 2000), that is, forming distinct and non-overlapping roles (prisoner and non-prisoner). According to Ashforth et al., role segmentation makes transition between roles (i.e., returning to the non-prisoner role) much harder, potentially extending the suffering experienced in prison into future life. Role segmentation is also likely to contribute to the disruption of social bonds with people outside of prison if such social bonds are "knifed off" during imprisonment (see Rocque, Bierie \& MacKenzie, 2011). Thus, a role segmentation approach to coping with prison life is likely to exacerbate loneliness and interpersonal suffering in the long term.

Some participants reported a more positive approach to managing their lengthy and unpredictable sentences. Retaining a sense of one's own identity and not succumbing to the prisoner role seemed to be instrumental in this: John described how being "my own man" was an important aspect of his ability to cope. ${ }^{14}$ This has implications for rehabilitation that are beyond the scope of this paper.

\footnotetext{
${ }^{14}$ John was also one of only two participants who had never been in prison prior to his current conviction and indeterminate sentence. This may help to explain why he was more able to retain a sense of his non-prisoner role/identity.
} 
A number of prisoners described the specific impact of prison on their ability to trust. John felt that "trust in prison is a very difficult thing". Peter described how showing emotion made prisoners vulnerable (see also De Viggiani, 2006):

In this environment you cannot show your weaknesses because you, you know, you got more inmates sat round you in these courses and some of them will take advantage of you being emotional.

In risk assessment interviews, prisoners are expected to disclose sensitive, personal information. Clearly some interviews are conducted in a context of feeling vulnerable and unable to trust others. Referring to Ashforth et al. (2000), this means that prisoners have to make a transition from the prisoner role that is defined by emotional guardedness, suspicion and distance from others, to the "risk assessment interview participant" role in which they are expected to be fully open about thoughts and feelings. Given that these roles are so distinct, transition is likely to be challenging (Ashforth et al., 2000) and may have to be enacted with very little warning, if messages about a planned risk assessment interview have not been communicated to a prisoner. The need to prepare for role transition may explain why seemingly minor inconveniences (such as cancelled appointments or no notice of appointments) take on greater significance in prison, as alluded to above. This underlines the importance of understanding the context in which risk assessment is conducted and how that context may influence the risk assessment interview (Crighton \& Towl, 2008; Shingler \& Needs, 2018b; Warr, 2008).

Some prisoners described the negative impact of the prison environment and their peers on risk assessment. Some prisoners "hear these horror stories [and] you believe them" (Shawn). John reported that he "managed to distance myself from the negativity, because, believe me, it is, if you get caught in that it is very difficult to break away from it". John believed that psychological risk assessment should happen very early in someone's sentence 
“because when somebody first comes into prison, you've got a very small window to capture them before they get all the negativity brought up". Prisoners are thus caught within a complex web of relationships in prison (Nolan \& Walsh, 2012) that have the potential to exert powerful influence on their expectations and behaviour (Pycroft, 2014), including within risk assessment. For example, collective opinion of psychologists as untrustworthy and adversarial could create expectations of untrustworthiness amongst prisoners who have never met a psychologist. This, in turn, potentially creates greater barriers for psychologists to overcome in the risk assessment interview - there is certainly evidence that expectations influence outcomes in other settings (Ross, Polaschek \& Ward, 2008). Similarly, Safran and Muran (2000) note how clients' interpersonal expectations and beliefs influence their behaviour, which in turn affects the behaviour of therapists. Expectations of untrustworthiness from prisoners will influence their behaviour in risk assessment interviews - how they respond to particular questions, the fullness of their answers, the openness with which they describe their current and previous difficulties. Psychologists will inevitably make interpretations and judgements about the nature of the prisoner's behaviour in the interview and how this might (or might not) relate to the nature and extent of his risk (Shingler \& Needs, 2018b). Awareness of these complex intersubjective processes is essential in breaking out of unhelpful and self-perpetuating patterns (Nolan \& Walsh, 2012; Pycroft, 2014). Safran and Muran (2000) describe the value of metacommunication in mending ruptures to the therapeutic alliance and this is equally relevant to the working relationship in risk assessment -psychologists having the knowledge and confidence to openly acknowledge and collaboratively reflect on prisoners' expectations, fears, barriers and suspicions is a step towards resolution. Additionally, reaching prisoners earlier in their sentences, before they are unduly influenced by the negative attitudes and expectations of others, could contribute to more engagement and cooperation with risk assessment. 
In summary, prisoners described the prison environment as characterised by violence, volatility and suffering. As risk assessment is conducted within this environment, it is reasonable to conclude that it is impacted by it (Harding, 2014; Hough, 2010; Rubin, 2017). The next section describes the two subordinate categories, which sit within the violent, volatile and suffering-inducing environment. The categories "Feeling Stuck, Powerless and Out of Control" and "Psychologists as Untrustworthy yet Powerful" describe more specifically the experiences of prisoners in relation to risk assessment.

Feeling stuck, powerless and out of control. Participants' descriptions of their reactions to receiving a life sentence reflected a sense that their futures were no longer their own and that they had become a tiny part of a much bigger system. For example:

The impact is incredible. It is, it is, it's incredible because you know, that light is very far off and you think about how am I going to get there? (John).

And:

When I got a long sentence I thought to myself, OK, I'll be able to address whatever they feel say I need to address beforehand. But every time I get closer, the goal posts, the goal posts get moved a bit further, yeah, understand? (Ezra)

These descriptions reflect a sense of stuckness and powerlessness. Experiences of indeterminate sentences as unrelenting and arbitrary were echoed by other prisoners as well as by commentaries on the IPP (Jacobson \& Hough, 2010; Strickland \& Garton-Grimwood, 2013). There was a sense of life being wasted by waiting around in prison for things that may or may not help you to progress. Peter described how he was "just sat here waiting for things to happen". Jude explained "I could wait two years to get a place on the assessment just to be told I don't need to do it, right?" The frustration of feeling "warehoused" whilst waiting for courses was noted by Blagden and Perrin (2016, p. 37). Jewkes (2005) similarly described 
pointless waiting, not knowing when, if ever, the indeterminate sentence would come to an end:

It's like I said to you, it's just, just dead end, it's just er, just wake up and think another day, another day, another day and that's how it works, it's just a total waste of time. (Peter)

Colin commented that his life sentence had "finished me, I've got nothing" and, like Peter's comment above, this reflected a sense of hopeless resignation about the situation. Similarly, Schinkel (2014) described a sense of resigned acceptance amongst her participants as a means of coping with long prison sentences. Prisoners' experiences of being stuck and lacking agency over their lives or the progression of their sentences (Goffman, 1961; Irwin \& Owen, 2005; Liebling, 2011) are particularly salient when it comes to risk assessment. As noted previously, ISPs are dependent on favourable risk assessments in order to progress through the prison system towards release. To this end, ISPs do not have control over their futures and can feel "powerless to do anything about it so you just get on with it" (Colin; and see Crewe, 2011; Goffman, 1961; Jewkes, 2005; Warr, 2008). As Ron said, “they don't know when they're going to walk out that door'. Risk assessment was experienced as an integral part of the lifer system and "part of the process really that you've gotta go through" (Colin); "part of the system" (Peter) and "part of the process of being a life sentenced prisoner" (Shawn), further reinforcing prisoners' lack of choice and control. Martin specifically stated that "I haven't got a choice in the matter" and Malcolm resigned himself to his powerlessness, "I know I'll have to do that anyway to get out as a lifer, I have to, you have to do what they tell you to do". Ezra recognised the subtleties of choice, in that he technically could refuse if he was willing to accept the consequences which, for ISPs, are potentially life changing: 
You have got a choice, innit, whether to go for that assessment or not to go for that assessment. But like I say there are always pros and cons, understand? And it's whether or not you are willing to take the consequences on board or not. These quotes suggested an absence of meaningful choice, compounding feelings of powerlessness, as reflected by Daniel: “I just feel like I don't know where I am. I feel helpless" (see Liebling, 2011). Added to this was the emotional burden of risk assessment: I've never been so stressed in my life like after my erm adjournment. This time a few weeks ago I had to go healthcare, like, I felt I was having a heart attack like. They said it's down to like stress and anxiety. (Daniel)

Thus, the negative experience of risk assessment was another element of the suffering described above. Participants described risk assessment as "daunting" (John and Jude) "horrible" (Colin), "terrible" (Ron), and "stressful", "scary", and "disconcerting" (Shawn; see also Attrill \& Liell, 2007, Crewe, 2011; Liebling, 2011). The "pains of risk assessment" (Shingler et al., 2017, p.4), then, are at least partly attributable to the lack of control over one's own destiny, the sense that one's future is in someone else's hands, and the arbitrary and opaque nature of risk assessment, as summed up by Jim:

I think the high stakes nature of risk assessment for ISPs is really important because you can sit there second guessing, have no idea what's going on, it's so nervewracking, particularly when you come up on on, erm, parole in an open prison, so terrified that any bit of information, you know, I walked on the grass yesterday, you know, is there going to be a report in about that? Not knowing what they think or what they know and erm it's just really terrifying. It is really terrifying. And that's not, I would that's not me saying that, it's really common amongst a lot of people I've known. 
Jim and also Shawn described trying to "second guess" the assessor's thoughts and opinions during assessment, and both were conscious of how things they had said or done (however trivial) might affect them. This is the backdrop to some risk assessment interviews: anxious and fearful prisoners trying to second guess the perspectives of assessors in order to navigate the high stakes process. Bringing these intersubjective issues into the forefront, for reflection and discussion, is a potential vehicle for resolution and progress (Safran \& Muran, 2000).

Whilst a number of prisoners described a lack of power over their lives and futures, others felt they had more influence over risk assessment decisions. John said he approached his sentence with clear goals, engaging immediately with the help he was offered in order to understand his offending and deal with the psychological problems that contributed to it. However, many prisoners are not equipped with this level of insight, skill and forethought. Indeed, a number of prisoners, whilst recognising the importance of risk assessment, did not seem to understand it or what they needed to do to influence it. Some participants did not understand static risk assessments and how they were calculated; others did not understand that risk assessment focused on the risk of future reoffending, and was not necessarily determined by good prison behaviour. When asked about what he thought a good risk assessment would be like, Colin responded “Er, a risk assessment, risk for, I don’t know really, cos I, risk for what?” Despite being in prison for over thirty years, Colin lacked understanding of risk assessment. Therefore it is unlikely he would feel he that he had any influence over his risk assessment. Colin's experiences seem not to be unique or even that unusual. A joint inspection of the management of life sentenced prisoners (Criminal Justice Joint Inspection, 2013) found that in many cases, uncertainty, inconsistency and confusion characterised the management of lifers throughout their sentences, with prison staff at times not knowing how to best advise life sentenced prisoners (Crewe, 2011). Shingler et al. 
(2017) discuss the importance of clarity and transparency in the risk assessment interview, and it seems that this needs to be extended to cover the process of the life sentence and risk assessment more generally. Encouragingly, there is motivation to make other aspects of the process, including Parole Board decision making, more transparent (Hardwick, 2017) which can only improve views of fairness (Tyler \& Huo, 2002) and hopefully increase the sense of risk assessment as collaborative (Shingler \& Mann, 2006; Shingler et al., 2017).

In addition to stress resulting from the implications of assessment, the actual process of assessment was experienced as stressful, including reliving details of offences, described by some as "frustrating" (Daniel) and "draining" (Shawn). Some prisoners felt the past was too heavily weighted in risk assessment - they wanted more focus on the future. Shawn described a positive assessment experience in which "there was positive engagement about the future and about how I felt about life. Not, not on a murder that happened twenty five years ago". John felt that being goal directed, and having a sense of hope for the future was central to his success. Malcolm explicitly described the value of hope for him, which a more future-focused assessment could provide:

Give em hope I suppose, by saying, "Oh, you will get out in the end, you will get through this". Cos a lot of time you don't hear it, you don't hear that mention. You don't hear like "You are, one day you are gonna get out" n'that yeah. You do hear it sometimes probably but I never heard it.

Similarly, Daniel believed that focusing on "the good stuff" would provide a more hopeful and balanced approach to assessment and intervention. This view is consistent with Attrill and Liell's (2007) recommendations about balancing risks with progress and future plans. It is also consistent with strengths-based approaches (Ward \& Stewart, 2003) which describe the advantages of broader and more positive intervention models, including increased motivation and more complete, holistic and individually relevant intervention and 
risk management planning. Exploring strengths and goals as well as problems and deficits in risk assessment could begin to overcome some of the hopelessness and stress experienced by prisoners.

Psychologists as untrustworthy yet powerful. On the whole, prisoners reported not trusting psychologists (see also Crewe, 2011 \& 2012; Maruna, 2011; Sparkes, 1998; Warr, 2008). A commonly held view was that psychologists were motivated to find reasons to keep prisoners incarcerated, for example, "I felt they were trying to nit-pick and keep me in for nothing really" (Colin). There was suspicion that psychologists deliberately try to entrap prisoners into disclosing things that would indicate risk - Malcolm described being asked "a trick question". Peter described how psychologists:

Ask you these repetitive questions, thinking you're not going to click on that they're repetitive questions about the same thing, wait for you to give a different answer, so then they can pounce on you and go, "Well you said this earlier, you said that earlier, and you said this earlier". They're just to catch you out, make your life in here longer. Warr (2008) similarly described feeling that psychologists were "not there to help me but to aid and abet the prison in controlling me" (p. 214). Warr's reflection suggests that he saw psychologists as representing another branch of the prison system or as "a generalized extension of correctional officers" (Gannon \& Ward, 2014, p. 440) rather than people there to support and facilitate rehabilitation. In that sense, psychologists may be seen more as representatives of the state rather than wholly independent professionals - this is likely to undermine trust and engagement.

For some men, mistrust of psychologists resulted from their own experiences in which they felt misled or misrepresented. For others, mistrust resulted from listening to prison talk about psychologists and risk assessment. Mistrust also seemed to be either created or exacerbated by a sense of distance from psychologists (Shingler \& Needs, 2018b): 
They are in the prison all day. The only time you see them if is they are risk assessing you, if they're doing a facility course. They don't want to sit down and interact with you on a normal - and I have to say that's a very bad approach. (Ezra)

Ezra went on to explain that "find[ing] time to engage with prisoners on a normal day to day basis" would make a substantial difference to working relationships between prisoners and psychologists in risk assessment. In the same way that prisoners described interpersonal distance and a lack of humanity as creating suspicion and hostility (Shingler et al., 2017), physical distance was seen as equally unhelpful. It was seen as reducing the opportunity for a "human connection" (Shingler et al., 2017) as well as reducing opportunities to break down barriers of suspicion and mistrust. It may also be that more informal contact with psychologists, more familiarity with the psychologist, their interpersonal style, expectations and ways of working eases role transition from prisoner to risk-assessment-participant roles (Ashforth et al., 2000, and see above), making the actual process of risk assessment less stressful for prisoners.

As well as being physically distant, prisoners felt that psychologists were experientially distant from them. There was a sense psychologists were so different from prisoners that they could not possibly understand them or their lives:

And psychologists are coming from, without, without no disrespect but you're coming from a normal, whatever you could class as normal but there the standard hierarchy or standing in life. You've never really gone without food, you've never been homeless, you've never had a dysfunctional family nine times out of ten, er, yeah, poor education. (Ron)

Clearly Ron was making assumptions about psychologists here, and there may well be psychologists working within HMPPS who have experienced significant life-course adversity. However, there is also likely to be some truth in Ron's perspective - in many 
cases, there is a substantial experiential distance between prisoners and psychologists. One area in which this is most apparent is that of age and gender: whilst specific figures are not available in the public domain, experience indicates that a large number of psychologists working in HMPPS are women, and many, especially those still in training, are likely to be much younger than the men they are assessing. Martin summed up his feelings of resentment about this:

They bring in trainees that are still studying, yet they're writing reports about us, that have a swing on our life and they're younger than us.

Having high stakes assessments completed by trainees was particularly challenging for some prisoners, and caused substantial resentment when there were "people with no experience, or very little life experience, having control over your life" (Jude). This reluctance to be assessed by trainees was also acknowledged by the psychologists' descriptions of the trainee dilemma (Shingler et al., 2019). Jim suggested that this resentment could be due to prisoners' misogynistic beliefs. Whilst this may be true, it is also possible that it is a completely normal reaction to having much younger people make life changing decisions, something which psychologists acknowledged (Shingler, et al., 2019). It is not unreasonable to want someone with skill and experience to make potentially life changing recommendations. There is no clear solution to this problem, other than substantial efforts in interviews to listen, understand, treat prisoners as individuals and make a human connection with them (Shingler et al., 2017). What was apparent from the prisoners' contributions was that being assessed by young, unqualified trainee psychologists undermined trust in the profession of psychology and affected views of the legitimacy of psychological assessment in general.

Another element to prisoners' mistrust of psychologists seemed to result from prisoners not feeling known or respected as individuals. A number of participants reported 
that psychologists paid too much attention to prisoners' files, and did not spend enough time with the prisoner himself: "cos the problem with some psychologists is like they can believe the paper too much they read, but not see the person" (Malcolm). Ross et al. (2008) similarly commented on the potential for correctional workers to make decisions about prisoners before meeting them, partly as a result of the allocation of pejorative labels within prison records. Jude, Colin, Peter, Shawn, Daniel and Ezra all valued feeling known as individuals. Shawn's comments suggested that spending more time with the psychologist in an assessment enabled him to overcome his barriers and experience her as more trustworthy, which in turn enabled him to discuss his problems more openly (Shingler et al., 2017):

It has been suggested that I'm sometimes too guarded and too defensive and not open enough with the professionals who I'm working with. I was so comfortable [when the psychologist spent more time with me] I could be completely open. Anything could be discussed and I didn’t feel uncomfortable discussing matters.

There was a view amongst the prisoner participants that having more contact and time with the psychologist resulted in a more accurate assessment. Peter directly attributed his dissatisfaction with his assessment to the lack of contact he had with the psychologist, commenting "how can someone form an opinion of you who's never met you?" (see also Crewe, 2011; Schinkel, 2014; Sparkes, 1998). Decisions that feel fairer elicit greater cooperation (Tyler \& Huo, 2002), and prisoners' comments suggested that greater contact with the psychologist is one requirement for the perception of fairness. More contact could also facilitate psychologists' ability to be responsive to the individual prisoner (Stiles, Honos-Webb \& Surko, 1998). However, this suggestion may cause consternation amongst some about the objectivity of assessments in such circumstances: whether psychologists are more vulnerable 
to bias when they know prisoners better ${ }^{15}$ (HMIP, 2006), or whether greater familiarity will result in unstructured clinical judgement interfering with risk assessment accuracy. In response to these arguments, firstly, it is arguable that superficial contact between psychologist and prisoner could exacerbate suspicion and hostility and bias information gathering in itself (Shingler \& Needs, 2018b). Secondly, although at the aggregate level ARAIs usually have greater predictive accuracy than clinical judgement, they fall short of being entirely accurate and they do not consistently outperform clinical judgement (Grove, Zald, Lebow, Snitz \& Nelson, 2000). There are also limitations with regard to using nomothetic data to make individual level predictions - Hart, Michie and Cooke (2007) suggest that individual level predictions arising from actuarial assessments are "virtually meaningless" (p. 60). ARAIs are limited and it is inevitable that clinical judgement will play a part in determining risk and need on an individual basis. There is a body of literature that discusses the balancing of theory with clinical expertise and experience (Gannon \& Ward, 2014; Lilienfeld, Ritschel, Lynne, Cautin, \& Latzman, 2013; Lowenkamp, Holsinger, Robinson \& Cullen, 2013), and the value of this approach in complex cases.

The final, and one of the most important, threads to prisoners' mistrust of psychologists was the view of psychologists as "the quiet ones with the power: what the psychologist says goes" (Shawn; see also Crewe, 2011; Sparkes, 1998; Warr, 2008). Psychologists were described as having "too much" power (Jude) and "having a lot of power and influence in sentences" (Shawn). Ron described the prison system as "psychology topheavy" where "everything's a mind game". Martin believed that it was the psychologist's

\footnotetext{
${ }^{15}$ Interestingly, Grove et al. (2000) suggested that bias might be a reason for clinical judgement not outperforming mechanical procedures, but did not make any comment about whether clinical judgement tended to result in false positive or more false negative predictions. Their commentary, pointing to the tendency in clinicians to overlook base rates, and their vulnerability to the representativeness and availability heuristics (see also Ireland, 2004) might suggest that clinicians are more vulnerable to false positives - predicting recidivism which does not occur.
} 
report that "tips the scales" for ISPs in parole decisions. Jim described his experience of psychologists' reports influencing parole decisions (Crewe, 2011):

If you've got an OM supporting you and a psychologist who's not, you're probably in trouble. If you've got a psychologist who's supporting you and your OM isn't, there's more chance I think. Even if your OM is the person that, if you've got a psychologist who says we think this person's got a $\mathrm{x}, \mathrm{y}, \mathrm{z}$, you know, puts a fancy looking name on it, you're really in trouble.

Arguably in a coercive environment, there is a power imbalance in all relationships and prisoners' general sense of powerlessness in prison is described above. However, something about the relationship between prisoners and psychologists brought power differences into sharper focus. For some prisoners, this was about the magnitude of the influence they perceived psychologists to have within the parole process (Shingler, 2017; Shingler, et al., 2019; see also Crewe, 2012; Warr, 2008). For others, resentment stemmed from the view that young and unqualified psychologists were not entitled to hold such power. For others, it was the power psychologists were perceived to have over the recording and interpretation of information that caused consternation. Written information is crucial to prisoners' progression and some prisoners felt that decisions about them were made on the basis of inaccurate information which they had no power to correct - errors would not be so problematic if they were inconsequential. Jude explained how incorrect details recorded in his prison file may have been removed, "but they still get used against me by psychologists and facilitators". Martin similarly described how something he said in an assessment was misinterpreted pejoratively in a psychological report:

Anyway she writ in there that I said that I wouldn't be upset or sad if my Nan died. Right now in my head I'm thinking hmm, I would never say something like that. For a start my Nan's like my mum so why would I? What I said to her was I wouldn't like 
mope around, I'd try and keep things goin and not be erm, cos I know she wouldn't want me to be like that. And what she's gone then is she's gone back and writ that I wouldn't be sad or upset.

There was a view from some prisoners that challenging errors made things worse for them, in that their challenging was likely to be interpreted through the lens of risk:

Daniel: I s'pose a lot of it depends on how the person puts themselves across y'know what I mean but, you know if you're told that you've got certain issue and you don't agree with that, and then you kind of like try and put it across, they'll make another issue. So not only have you got the issue you don't agree with, you know, like you know, like mine - like kind of, I explained a few things, I got then minimisation of culpability put as a risk factor. D’you know what I mean? But it's like... Interviewer: Yes I understand, so when you try and challenge something almost the process of challenging it that becomes a problem?

Daniel: Exactly yeah. So it's like it's a difficult situation like. Sometimes you just feel like, I mean I often describe, I feel like a dog with a choke chain. D'you know what I mean? You know, it's, it's, you know every time it's like you feel you wanna kind of, be you and you know, walk off in this direction or go and you know do something, it's like getting yanked back. It feels like you're being choked, like, it's just it's very difficult.

Daniel's comments summed up the sense of powerlessness generally, and in particular how a lack of control over written information contributed to this. Liebling (2011) also reported that prisoners felt unable to challenge things they disagreed with in case it went against them. Prisoners seemed to feel they were in a lose-lose situation (a "double-bind", Bateson, Jackson, Haley \& Weakland, 1956, p. 251) - if they challenged something, it could 
go against them, if they did not challenge something, wrong information could be recorded which might end up being used in an assessment. Jim noted how mistakes become fact: And you know in some examples, there are, are objective fictions in it, it's actually just wrong in some points. And it then becomes a battle whether you say, ok they say I was 16 when this happened but actually I was 18 . Do I just, cos I've tried to battle this and I can't prove it, do I just accept that I was 16 and we'll go with the truth that I was 16 even though I was 18 , and it can be really quite, it can be really quite, erm, straightforward things that are just wrong that end up kind of becoming the truth. Jim described the "psychological portfolio" that built up on ISPs over the course of a sentence, and in his view, psychological information became almost an entity in itself. Sam (psychologist) recognised the control psychologists had over information, for example, "[the prisoner] explains what he thinks about that, there might be some discussion about it, but ultimately it goes down as I have said it's gonna go down". It is easy to see how this could undermine the relationship between prisoners and psychologists: when prisoners felt clear about a truth yet saw psychologists as insisting on their version of the truth this could be experienced as "your risk assessment is done with their answers not your answers" (Jude). It is important to note here that both psychologists and prisoners in this research provided examples of incorrect facts being included in prisoner files - so feeling that incorrect information is being held and used to inform decisions about the future (from a prisoner's perspective) is not necessarily a consequence of denial or prisoners' paranoia or suspicion. In addition to information being interpreted wrongly, recorded wrongly, and being seemingly set in stone, prisoners also described the lack of control they had over psychological assessment reports. Prisoners described querying reports, yet little or nothing was changed: 
You might be asked to briefly have a meeting, anything you want to say about it? Yeah, we'll take that on board. And then you're sent away and quite often nothing changes anyway. (Shawn)

Jim expressed a similar view, and noted that despite assurances, there was often little collaborative discussion of reports:

One thing that I think is that erm, in terms of something feeling collaborative, is that before it becomes set in stone, that actually there is a process whereby you can talk, you know, you can talk about things and things can be changed ... In a report for example, and that doesn't tend to happen (Jim)

Some prisoners interpreted refusal to change reports as evidence of the psychologists' power over information. Jim's comment above suggested that he would value greater explicit negotiation about the content of reports (Safran \& Muran, 2000). A greater focus on negotiation throughout the assessment process might also be useful - part of the discussions around consent might focus on how the psychologist and prisoner might deal with any disagreements, or how the report could be most usefully disclosed to the prisoner. This level of explicit responsiveness (Stiles et al., 1998) communicates a genuine commitment to collaboration and to individually-relevant practice, both of which have been identified as elements of a good interpersonal approach to risk assessment (Shingler et al., 2017). It is also arguable that such mutually responsive, intersubjective approaches could provide the basis for meaningful interpersonal change and development (Salvatore, Gelo, Gennaro, Manzo \& Al Radaideh, 2010).

Finally, whilst the majority of the prisoners in the sample reported some negative views about psychologists, there were examples of more positive attitudes. Malcolm believed that psychologists were "there to help you, innit". Daniel believed "psychology and that you 
know, is value, you know can be a valuable thing and it's helped me a lot you know". John explained:

A psychologist is a professional person, right? They’ve done probably a degree, a masters or a doctorate right? They are, er, professional in their field erm and I'm quite happy with a professional doin' their job with me because I know that I had a problem that needed to be helped with.

There was a sense of respect for psychological knowledge in these comments. Additionally, just as some psychologists empathised with prisoners who did not want to be assessed by trainees, some prisoners empathised with the challenges of training psychologists in risk assessment:

They are training but they have to learn in the real world setting. A chef doesn't stay at home and cook in the kitchen he goes into er, a restaurant kitchen to train in the field, so it's got to be done. (Shawn)

Similarly, Malcolm explicitly empathised with the challenges faced by psychologists in risk assessment:

Malcolm: but it's hard it must be a hard job being a psychologist, you're a psychologist right?

Interviewer: I'm a psychologist, yeah

Malcolm: it must be a hard job, innit? you gotta make decisions about people

Interviewer: it is hard yeah

Malcolm: weigh em up, ‘n’ you gotta get it right

Thus, both psychologists and prisoners recognised and empathised with each other's challenges. Perhaps bringing this empathy and understanding into risk assessment, and explicitly naming and exploring some of the challenges is a step towards resolving them, thereby providing a starting point for intersubjective engagement. 


\section{Summary and conclusions}

Prisoners interviewed for this study described risk assessment as being conducted within a context of violence, volatility and suffering. They experienced emotional and relational isolation within a prison system perceived as harsh, arbitrary and controlling. Some prisoners reported a sense of hopeless resignation: the system will never change, yet prisoners are part of it and have no choice but to go along with it if they want to progress. Risk assessment was seen as an integral part of the system, and created feelings of powerlessness, uncertainty and fear. Added to this was a view of psychologists as untrustworthy but unjustifiably powerful. Some prisoners perceived psychologists as aloof and removed from them and their lives, with little concern for prisoners' individuality. There was a general feeling of resentment about psychologists' power, particularly when prisoners felt that the psychologist in question was not entitled to hold it (as in the case of young and unqualified psychologists). This context is particularly challenging when considering what is required of prisoners in risk assessment interviews. They are asked to reflect in depth on their offending, as well as on the psychological, social and environmental problems that they have experienced throughout their lives, at all times knowing that the outcome of the interview could mean the difference between possible release, move to a lower security, "open" prison, or a further lengthy period of incarceration.

There were also some reports of positive experiences of psychological risk assessment. Those who managed to navigate the system and had more positive attitudes to it could distance themselves from prison negativity, get clear and supportive advice from staff, and retain a goal-oriented approach to their sentence and their futures. There was also evidence of mutual understanding and empathy between prisoners and psychologists. A more explicitly responsive and collaborative approach to risk assessment that brings some of these 
challenging issues into the forefront might be a step towards a more engaging risk assessment experience, in which prisoners can feel that they have more of a stake. 


\section{References}

Ashforth, B., Kreiner, G., \& Fugate, M. (2000). All in a day's work: Boundaries and micro role transitions. The Academy of Management Review, 25(3), 472-491.

Attrill, G., \& Liell, G. (2007). Offenders' view on risk assessment. In N. Padfield (Ed.), Who to release? Parole, fairness and criminal justice (pp. 191-201). Willan Publishing, Cullumpton, Devon, UK.

Austin, W., Kagan, L., Rankel, M., \& Bergum., V. (2008). The balancing act: Psychiatrists' experience of moral distress. Medical Health Care and Philosophy, 11, 89-97.

Barnett, G. D \& Mann, R. E (2011). Good lives and risk assessment: Collaborative approaches to risk assessment with sexual offenders. In H. Kemshall, and B. Wilkinson (Eds.), Good Practice in Assessing Risk: Current Knowledge, Issues and Approaches (pp. 139-154). London: Jessica Kingsley.

Bateson, G., Jackson, D. D., Haley, J., \& Weakland, J. (1956). Toward a theory of schizophrenia. Systems Research and Behavioral Science, 1(4), 251-264.

Blagden, N., \& Perrin, C. (2016). "Relax lads, you're in safe hands here”: Experiences of a sexual offender treatment prison. In C. Reeves (Ed.), Experiencing Imprisonment: Research on the experience of living and working in carceral institutions (pp. 30-38). Abingdon, Oxon: Routledge.

Bowers, L., \& Friendship, C. (2017). Forensic psychological risk assessment for the Parole Board. In K. Browne, A. R. Beech, L. A. Craig \& S. Chou (Eds.), Assessments in forensic practice: A handbook (pp. 103-121). Chichester UK: John Wiley \& Sons, Ltd.

Butler, M. (2008). What are you looking at? Prisoner confrontations and the search for respect. The British Journal of Criminology, 48(6), 856-873. 
Charmaz, K. (2006). Constructing grounded theory: A practical guide through qualitative analysis. London, UK: Sage

Crawley, E. (2004). Doing prison work: The public and private lives of prison officers. Cullumpton, Devon, UK: Willan Publishing.

Creswell, J. W., \& Miller, D. L. (2000). Determining validity in qualitative inquiry. Theory into Practice, 39(3), 124-130.

Crewe, B. (2011). Depth, weight, tightness: revisiting the pains of imprisonment. Punishment and Society, 13(5), 509-529.

Crewe, B. (2012). The prisoner society: Power, adaptation and social life in an English prison. Oxford, UK: Oxford University Press.

Crighton, D. A. (2010). Assessment. In G. J. Towl \& D. A. Crighton (Eds.), Forensic psychology (pp. 244-259). Oxford, UK: BPS/Blackwell.

Crighton, D. A., \& Towl, G. J. (2008). Psychology in prisons (2 ${ }^{\text {nd }}$ ed). Oxford, UK : BPS/Blackwell.

Criminal Justice Joint Inspection (2013). A Joint Inspection of Life Sentence Prisoners: A Joint Inspection by HMI Probation and HMI Prisons. Retrieved from https://www.justiceinspectorates.gov.uk/probation/wpcontent/uploads/sites/5/2014/03/life-sentence-prisoners.pdf

Dematteo, D., Batastini, A., Foster, E \& Hunt, E (2010). Individualising risk assessment: balancing idiographic and nomothetic data. Journal of Forensic Psychology Practice, 10(4), 360-371.

De Viggiani, N. (2006). Surviving prison: exploring prison social life as a determinant of health. International Journal of Prisoner Health, 2(2), 71-89.

De Viggiani, N. (2007). Unhealthy prisons: exploring structural determinants of prison health. Sociology of Health and Illness, 29(1), 115-135. 
Edwards, D., \& Potter, J. (1992). Discursive psychology (Vol. 8). London, UK: Sage.

Engineer, C., \& Rogers, J. (2018, August $14^{\text {th }}$ ). Taxi sex attacker: Who is John Worboys, what were his sex attack crimes and why was the Black Cab rapist nearly freed from prison? The Sun, retrieved from https://www.thesun.co.uk/news/5272347/johnworboys-black-cab-rapist-sex-attack-prison-parole-board-taxi/

Gannon, T. A., \& Ward, T. (2014). Where has all the psychology gone? A critical review of evidence-based psychological practice in correctional settings. Aggression and Violent Behaviour, 19, 435-446.

Glaser, B. G., \& Strauss, A. L. (1967). The discovery of grounded theory: Strategies for qualitative research. New Brunswick, NJ: AldineTransaction.

Goffman, E. (1961). Asylums: essays on the social situation of mental patients and other inmates. Harmondsworth, Middlesex, UK: Pelican.

Grove, W. M., Zald, D. H., LeBow, B. S., Snitz, B. E., \& Nelson, C. (2000). Clinical versus mechanical prediction: A meta-analysis. Psychological Assessment, 12, 19-30.

Hanson, R. K., \& Morton-Bourgon, K. (2004). Predictors of sexual recidivism: An updated meta-analysis. Ottawa, Ontario: Public Works and Government Services, Canada.

Hanson, R. K., \& Morton-Bourgon, K. E. (2009). The accuracy of recidivism risk assessments for sexual offenders: a meta-analysis of 118 prediction studies. Psychological Assessment, 21(1), 1-21.

Harding, R (2014). Rehabilitation and prison social climate: Do 'What Works' rehabilitation programmes work better in prisons that have a positive social climate? Australian and New Zealand Journal of Criminology, 47(2) 163-175.

Hardwick, N. (November, 2017). Parole - 50 years and counting. Presentation given to The Butler Trust, The Parole Board and HM Prison and Probation Service conference, Parole, Probation and Prisons - Past Present and Future. London. 
Hart, S. D., Michie, C., \& Cooke, D. J. (2007). Precision of actuarial risk assessment instruments: Evaluating the "margins of error" of group v. individual predictions of violence. The British Journal of Psychiatry, 190(49), 60-65.

Heilbrun, K., Yasuhara, K., \& Shah, S. (2014). Violence risk assessment tools: Overview and critical analysis. In R. K. Otto and K. D. Douglas (Eds.), Handbook of Violence Risk Assessment, (pp. 1-18). New York: Routledge.

Her Majesty's Inspectorate of Probation (2006). An independent review of a serious further offence case: Anthony Rice. Retrieved from www.justice.gov.uk/downloads/publications/inspectoratereports/hmiprobation/anthonyricereport-rps.pdf

Hough, M. (2010). Gold standard or fool's gold: the pursuit of certainty in experimental criminology. Criminology and Criminal Justice, 10(1), 11- 22.

Ireland, J. L. (2004). Compiling forensic risk assessment reports. Forensic Update 77, 15-22. Irwin, J., \& Owen, B. (2005). Harm and the contemporary prison. In A. Liebling \& S. Maruna (Eds.), Effects of imprisonment, (pp. 94-117). Uffculme, Devon, GBR: Willan PublishingIreland, J. L., (2004). Compiling forensic risk assessment reports. Forensic Update 77, 15-22

Jacobson, J., \& Hough, M. (2010). Unjust Deserts: Imprisonment for Public Protection. London: Prison Reform Trust.

James, E. (2003). A life inside: A prisoner's notebook. London: Atlantic Books. Jewkes, Y. (2005). Loss, liminality and the life sentence: Managing identity through a disrupted lifecourse. In A. Liebling \& S. Maruna (Eds.) Effects of imprisonment, (pp. 366-388). Uffculme, Devon, GBR: Willan Publishing. 
Leventhal, G. S. (1976). Fairness in social relationships. In J. Thibault, J. Spence, \& R. Carson (Eds.), Contemporary topics in social psychology (pp. 211-239). Morristown, NJ: General Learning Press.

Liebling, A. (2011). Moral performance, inhuman and degrading treatment and prison pain. Punishment \& Society, 13(5), 530-550.

Liebling, A., \& Maruna, S. (2005). Introduction: The effects of imprisonment revisited. In A. Liebling and S. Maruna (Eds.), Effects of imprisonment (pp. 1-29). Uffculme, Devon, GBR: Willan Publishing.

Lilienfeld, S. O., Ritschel, L. A., Lynne, S. J., Cautin, R. L., \& Latzman, R. D. (2013). Why many clinical psychologists are resistant to evidence-based practice: Root causes and constructive remedies. Clinical Psychology Review, 7, 883-900.

Logan, C. (2013). Risk assessment: Specialist interviewing skills for forensic practitioners. In C. Logan \& L. Johnstone (Eds.), Managing clinical risk: A guide to effective practice (pp.259-292). Oxford: Routledge.

Lowenkamp, C. T., Holsinger, A. M., Robinson, C. R. \& Cullen, F. T. (2012). When a person isn’t a data point: Making evidence-based practice work. Federal Probation 76(3), $11-21$

Marshall, W. L. (1994). Treatment effects on denial and minimization in incarcerated sex offenders. Behaviour Research and Therapy, 32(5), 559-564.

Maruna, S. (2011). Why do they hate us? Making peace between prisoners and psychology. International Journal of Offender Therapy and Comparative Criminology, 55(56), 671-675.

Ministry of Justice (2011). National security framework, categorisation function: Categorisation and recategorisation of adult male prisoners (Prison Service Instruction 40/2011). Retrieved from 
www.justice.gov.uk/downloads/offenders/psipso/psi-2011/psi-40-2011-

categorisation-adult-males.doc

Ministry of Justice (2019). Offender management statistics bulletin, England and Wales. https://assets.publishing.service.gov.uk/government/uploads/system/uploads/attachme nt data/file/775078/offender-management-quarterly-q3-2018.pdf

Nolan, G., \& Walsh, E. (2012). Caring in prison: The intersubjective web of professional relationships. Journal of Forensic Nursing 8, 163-169.

Parole Board (2018). Parole Board information on Indeterminate Sentence Prisoners (ISPs). Retrieved from https://www.gov.uk/government/news/parole-board-information-onindeterminate-sentence-prisoners-isps

Proulx, J., Tardif, M.., Lamoureux, B., \& Lussier, P. (2000). How does recidivism risk assessment predict survival? In D. R. Laws, S. M. Hudson, \& T. Ward, (Eds.), Remaking relapse prevention with sex offenders: A sourcebook (pp. 466-484). Thousand Oaks, CA: Sage Publications.

Pycroft, A. (2014). Complexity theory: An overview. In A. Pycroft \& C. Bartollas (Eds.), Applying complexity theory: Whole systems approaches to criminal justice and social work, (pp. 13-37). Bristol, UK: Policy Press.

Rocque, M., Bierie, D. M., \& MacKenzie, D. L. (2011). Social bonds and change during incarceration: Testing a missing link in the re-entry research. International Journal of Offender Therapy and Comparative Criminology, 55(5), 816-838.

Ross, E. C., Polaschek, D. L., \& Ward, T. (2008). The therapeutic alliance: A theoretical revision for offender rehabilitation. Aggression and Violent Behavior, 13(6), 462-480.

Rubin, A. T. (2017). Resistance as agency? Incorporating the structural determinants of prisoner behaviour. British Journal of Criminology, 57, 644-663. 
Salvatore, S., Gelo, O., Gennaro, A., Manzo, S., \& Al Radaideh, A. (2010). Looking at the psychotherapy process as an intersubjective dynamic of meaning-making: A case study with discourse flow analysis. Journal of Constructivist Psychology, 23(3), $195-$ 230.

Safran, J. D., \& Muran, J. C. (2000). Resolving therapeutic alliance ruptures: Diversity and integration. Journal of Clinical Psychology, 56(2), 233-243.

Schinkel, M. (2014). Being imprisoned: punishment, adaptation and desistance. Basingstoke, Hampshire, UK: Palgrave Macmillan.

Shingler, J. (2017). Psychologists' role in Parole Board decision making: What do Parole Board members think about psychological assessment? Forensic Update, 126. 22-27.

Shingler, J. (2019). Understanding psychological risk assessment: Exploring the Experiences of Psychologists, Indeterminate Sentenced Prisoners and Parole Board Members (Unpublished doctoral dissertation). University of Portsmouth, Hampshire, United Kingdom.

Shingler, J., \& Mann, R. E. (2006). Collaboration in clinical work with sexual offenders: treatment and risk assessment. In W. L. Marshall, Y. M. L. Fernandez, L. E. Marshall, \& G. A. Serran, (Eds). Sexual offender treatment: Controversial issues (pp. 225-239). Chichester, UK:

Shingler, J., \& Needs, A. (2018a). The role of psychological risk assessment in Parole Board decision making: An exploration of the perspectives of psychologists, indeterminate sentenced prisoners and Parole Board members. Prison Service Journal, 237, 36-40.

Shingler, J., \& Needs, A. (2018b). Contextual influences in prison-based psychological risk assessment: Problems and solutions. In G. Akerman, A. Needs \& C. Bainbridge (Eds). Transforming environments and rehabilitation: A guide for practitioners in forensic settings and criminal justice, (pp. 323-347). Abingdon, UK: Routledge. 
Shingler, J., Sonnenberg, S. J., \& Needs, A. (2017). Risk assessment interviews: Exploring the perspectives of psychologists and indeterminate sentenced prisoners in the United Kingdom. International Journal of Offender Therapy and Comparative Criminology, $62(10), 3201-3224$.

Shingler, J., Sonnenberg, S., \& Needs, A. (2019). "Their life in your hands": The experiences of prison-based psychologists conducting risk assessments with indeterminate sentenced prisoners in the United Kingdom. Psychology, Crime and

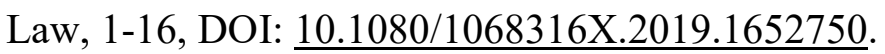

Sim, J. (1994). 'Tougher than the rest?' Men in Prison. In T. Newburn \& E. Stanko (Eds.), Just boys doing business: Men, masculinities and crime. London: Routledge.

Sparks, C. (1998). Lifers'views of the lifer system: Policy versus Practice. London: Prison Reform Trust.

Stein, J. Y., \& Tuval-Mashiach, R. (2015). Loneliness and isolation in life-stories of Israeli veterans of combat and captivity. Psychological Trauma: Theory, Research, Practice and Policy, 7(2), 122.

Stiles, W. B., Honos-Webb, L., \& Surko, M. (1998). Responsiveness in psychotherapy. Clinical Psychology: Science and Practice, 5(4), 439-458.

Strickland, P., \& Garton Grimwood, G (2013). The abolition of sentences of Imprisonment for Public Protection. House of Commons Library: Home Affairs Section.

Sykes, G. M. (1958). The Society of Captives: A study of a maximum security prison. Princeton, NJ: Princeton University Press.

Tyler, T. R. (1990). Why people obey the law: Procedural justice, legitimacy, and compliance. New Haven, CT: Yale University Press.

Tyler, T. R., \& Huo, Y. J. (2002). Trust in the law: Encouraging public cooperation with the police and courts. New York: Russell Sage Foundation. 
Urquhart, C. (2013). Grounded theory for qualitative research: A practical guide. London, UK: Sage.

Vess, J., Ward. T., \& Yates, P. M. (2017). The ethics of risk assessment. In K. D. Browne, A. R. Beech, L. A. Craig. \& S. Chou. Assessment in Forensic Practice: A Handbook. (pp. 370-386). Chichester, UK: John Wiley \& Sons Ltd.

Ward T., \& Stewart C. A. (2003). The treatment of sex offenders: Risk management and good lives. Professional Psychology: Research and Practice, 34(4), 353-360.

Warr, J. (2008). Personal reflections on prison staff. In J. Bennett, B. Crewe \& A. Wahidin, (Eds.), Understanding prison staff, (pp. 17-29). Willan Publishing, Cullumpton, Devon, UK. 
Table 1

Description of Prisoner Participants

\begin{tabular}{|c|c|c|c|c|c|c|}
\hline Pseudonym & Age & Ethnicity $^{16}$ & $\begin{array}{c}\text { Type of } \\
\text { Indeterminate } \\
\text { Sentence }\end{array}$ & $\begin{array}{c}\text { No. } \\
\text { Previous } \\
\text { Custodial } \\
\text { sentences }\end{array}$ & $\begin{array}{l}\text { Length of } \\
\text { time } \\
\text { served on } \\
\text { current } \\
\text { sentence } \\
\text { (years) }\end{array}$ & $\begin{array}{c}\text { Pre or } \\
\text { post } \\
\text { tariff? }\end{array}$ \\
\hline John & 47 & $\begin{array}{l}\text { White } \\
\text { British }\end{array}$ & $\mathrm{IPP}^{17}$ & 0 & 8 & pre \\
\hline Jude & 51 & $\begin{array}{l}\text { White } \\
\text { British }\end{array}$ & $\begin{array}{l}\text { Discretionary } \\
\text { Life }\end{array}$ & 2 & 5 & pre \\
\hline Colin & 52 & $\begin{array}{l}\text { White } \\
\text { British }\end{array}$ & Life & 0 & 34 & post \\
\hline Ron & 57 & English & $\begin{array}{c}\text { Automatic } \\
\text { Life Sentence }\end{array}$ & 5 & 19 & post \\
\hline Malcolm & 50 & $\begin{array}{l}\text { Black } \\
\text { British }\end{array}$ & $\begin{array}{l}\text { Discretionary } \\
\text { Life }\end{array}$ & 10 & 8 & post \\
\hline Peter & $\begin{array}{l}\text { Not } \\
\text { given }\end{array}$ & British & $\begin{array}{l}\text { Discretionary } \\
\text { Life }\end{array}$ & 2 & 4 & pre \\
\hline Shawn & 49 & $\begin{array}{l}\text { White } \\
\text { British }\end{array}$ & Life & 1 & $19 \frac{1}{2}$ & post \\
\hline Daniel & 37 & White & Life & 2 & 16 & pre \\
\hline Martin & 26 & $\begin{array}{l}\text { Mixed } \\
\text { Race }\end{array}$ & IPP & 1 & 7 & post \\
\hline Ezra & 38 & $\begin{array}{c}\text { Black } \\
\text { Caribbean }\end{array}$ & IPP & 2 & 10 & post \\
\hline
\end{tabular}

${ }^{16}$ Prisoners were asked to describe their ethnicity in their own words.

17 "IPP" is an abbreviation of "Indeterminate Sentence for Public Protection". The IPP was abolished in 2012 and is therefore no longer available to the courts. More information about the indeterminate sentences currently available to the courts in the UK can be found at www.sentencingcouncil.org.uk/about-sentencing/types-ofsentence/life-sentences/ 
Figure 1. Indeterminate sentenced prisoners' experiences of psychological risk assessment

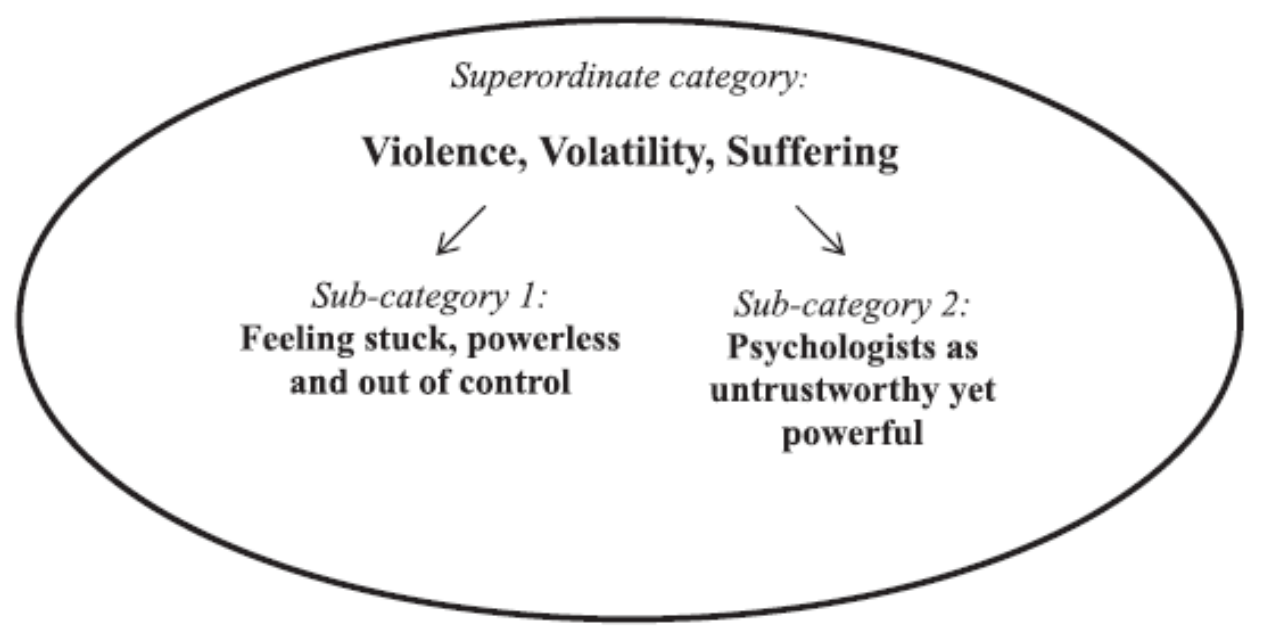

